\title{
Simulation of tides, residual flow and energy budget in the Gulf of California
}

\author{
Noel CARBAJAL *s, Jan O. BACKHAUS \\ Institut für Meereskunde, Universität Hamburg, Troplowitzstrasse 7, D 22529 Hamburg, Germany \\ $\S$ Correspondence address: Instituto de Ciencas del Mar y Limnologia, UNAM, Estacion de Investigaciones Marinas \\ Mazatlan, Apdo postal 811, 82040 Mazatlan, Sinaloa, Mexico
}

(Received 05/11/96, revised 30/07/97, accepted 01/08/97)

\begin{abstract}
With the application of a two-dimensional nonlinear hydrodynamical-numerical semi-implicit model, the principal tides $M_{2}, S_{2}, K_{2}, N_{2}, K_{1}, P_{1}$ and $O_{1}$ were studied. Energy budgets of the semi-diurnal $M_{2}$ and $S_{2}$ were calculated separately. The linear sum of these budgets was compared with the tidal energy budget obtained when these two tidal constituents interact. Since a quadratic form for the bottom friction was used, remarkable differences were found. The results show that in the area of the Colorado River delta, the dissipation of tidal energy is very strong. Intense tidal currents were observed in the same region and over the Salsipuedes Sill. Energy budgets calculated for forcing waves of different periods, but of the same amplitude, were used to estimate the principal periods of resonance. Although the topography of the Gulf is very complex, the model reproduced observed sea-surface elevation and current patterns. To study spring tide conditions, the above seven tidal constituents were simulated. Estimates of residual currents reveal the presence of several intense cyclonic and anticyclonic gyres. Over the Salsipuedes Sill, residual currents of the $M_{2}$ tide reach values of more than $15 \mathrm{~cm} \mathrm{~s}^{-1}$. Horizontal distributions of dissipation rates of tidal energy and of kinetic energy were also obtained. (C) Elsevier, Paris
\end{abstract}

\section{numerical modelling / tide / residual flow / energy budget / Seiche}

Résumé - Modélisation de la marée, du courant résiduel et du bilan énergétique dans le golfe de Californie. Les principales composantes de la marée $M_{2}, S_{2}, K_{2}, N_{2}, K_{1}, P_{1}$ et $O_{1}$ ont été étudiées à l'aide d'un modèle numérique bidimensionnel semi-implicite simulant les équations hydrodynamiques non linéaires. Les bilans énergétiques des ondes semi-diurnes $M_{2}$ et $S_{2}$ ont été calculés séparément; leur somme linéaire est comparée au bilan obtenu lorsque ces deux composantes interagissent; les différences importantes sont dues à la forme quadratique du frottement sur le fond. Les résultats indiquent une très forte dissipation de l'énergie de marée vers le delta du fleuve Colorado, où des courants de marée intenses sont observés, comme sur le seuil de Salsipuedes. Les bilans énergétiques calculés avec un forçage par des vagues de périodes différentes, mais de mêmes amplitudes, permettent d'estimer les principales périodes de résonance. Bien que la topographie du golfe soit très complexe, le modèle reproduit les élévations de la surface libre et les courants observés. Les sept composantes de la marée ont été calculées pour simuler les conditions de la marée au printemps. Les courants résiduels estimés révèlent la présence de tourbillons intenses, cycloniques et anticycloniques dans la partie nord du golfe. Sur le seuil de Salsipuedes, les courants résiduels de l'onde $M_{2}$ atteignent des valeurs dépassant $15 \mathrm{~cm} \mathrm{~s}^{-1}$. Les répartitions horizontales des taux de dissipation de l'énergie de la marée et de l'énergie cinétique sont également présentées. (C) Elsevier, Paris

modèle numérique / marée / courant résiduel / bilan énergétique / seiche

\footnotetext{
* Correspondence and reprints.
} 


\section{List of Symbols}

$\phi \quad$ latitude

$\lambda$ longitude, wavelength (m)

$t$ time (s)

$U$ transport (west-east) $\left(\mathrm{m}^{2} \mathrm{~s}^{-1}\right)$

$V$ transport (south-north) $\left(\mathrm{m}^{2} \mathrm{~s}^{-1}\right)$

$\zeta$ sea-surface elevation (m)

$R=6371040$ earth radius $(\mathrm{m})$

$H$ depth (m)

$g=9.81$ acceleration due to gravity $\left(\mathrm{mI} \mathrm{s}^{-2}\right)$

$\tau \quad=$ period of resonance $(\mathrm{h})$

$T \quad=$ tidal period $(\mathrm{s})$

$r \quad=0.0035$ friction coefficient

$\Delta \phi$ phase error

$A_{H}$ horizontal coefficient of eddy viscocity $\left(\mathrm{m}^{2} \mathrm{~s}^{-1}\right)$

$u_{e}$ eulerian residual current

$u_{L} \quad$ Lagrangian residual current

$u_{t}$ residual transport velocity

$u \quad$ vertically averaged velocity in the zonal direction $\left(\mathrm{m} \mathrm{s}^{-1}\right)$

$v \quad$ vertically averaged velocity in the meridional direction $\left(\mathrm{m} \mathrm{s}^{-1}\right)$

$u_{f}$ a velocity function $\left(\mathrm{m} \mathrm{s}^{-1}\right)$

$x \quad$ space variable $(\mathrm{m})$

$z \quad$ space variable $(\mathrm{m})$ (positive upwards)

$E_{k} \quad$ kinetic energy $(\mathrm{J})$

$E_{p} \quad$ potential energy (J)

$E_{b}$ rate of bottom dissipation of energy $\left(\mathrm{J} \mathrm{s}^{-1}\right)$

$E_{v} \quad$ rate of energy dissipation by eddy viscocity $\left(\mathrm{J} \mathrm{s}^{-1}\right)$

$E_{f}$ energy flux at the open boundary $\left(\mathrm{J} \mathrm{s}^{-1}\right)$

$Q$ factor of resonance

$M$ mean torque with respect to the axis

of the earth's rotation (J)

$\bar{E}_{\text {rot }}$ rotational energy $\left(\mathrm{J} \mathrm{s}^{-1}\right)$

c phase velocity $\left(\mathrm{m}^{2} \mathrm{~s}^{-1}\right)$

\section{INTRODUCTION}

Tides in semi-enclosed areas, such as gulfs or bays, are determined primarily by the gravitational attraction (tidegenerating force) of sun and moon, and by co-oscillation with tidal waves propagating in a neighbouring sea or ocean. The direct effect of the tide-generating force plays only a corrective role, and is usually not considered when calculating tidal parameters of these zones. In the Gulf of California, the contribution to energy balance and to surface elevation in this way is small. Therefore, the co- oscillation with tidal waves propagating in the eastern Pacific Ocean is by far the decisive factor in the tidal dynamic.

The water masses between the peninsula of Baja California and the mainland coast of Mexico constitute an extremely interesting region for oceanographic research in general. The stimulation of one of the most spectacular and dangerous tides in the world [17] combined with other forcing components such as wind, intense solar heating and communication with the open Pacific Ocean, produces, after interaction with a complex topography, a variable and vigorous circulation [3]. In relation to tides, a series of physical phenomena such as mixing processes, strong dissipation of tidal energy, internal waves etc., has been observed, cithcr by way of the analysis of systematic measurements or from satellite images. Tides, therefore, play a relevant role in the dynamic of the Gulf.

The Gulf of California is a marginal sea on the east side of the North Pacific Ocean (see figure 1, where the topography and a general view of the region is given). It has a length of approximately $1100 \mathrm{~km}$, measured from the mouth of the Colorado River to Cabo San Lucas. The Gulf is oriented from the northwest to southeast and lies between $23^{\circ} \mathrm{N}$ and $32^{\circ} \mathrm{N}$, and $106^{\circ} \mathrm{W}$ and $115^{\circ} \mathrm{W}$. Its geographical form approximates a channel with a width varying between 100 and $350 \mathrm{~km}$. The Gulf is divided into two oceanographic provinces. The upper Gulf can be considered as a continental shelf with an average depth of about $200 \mathrm{~m}$. In this area the topography is relatively simple. The region near the mouth of the Colorado River is particularly flat and very shallow. The Ballenas Channel and the Salsipuedes Basin, lying between Baja California and the island Angel de la Guarda, are exceptions where depths up to $1600 \mathrm{~m}$ can be found. The Ballenas Channel is very narrow (less than $20 \mathrm{~km}$ ) and has a length of $125 \mathrm{~km}$. The Infiernillo Channel lying between Tiburon and the mainland coast of Mexico is very flat and narrow and unimportant to the circulation in the Gulf. The flow over the Salsipuedes Sill and along the Ballenas Channel plays an essential role in the water exchange between the northern and southern parts of the Gulf. A series of basins (Guaymas, Carmen, Farallon and Pescadero), partially or well defined through sills, characterizes the lower Gulf. Depths increase from $2000 \mathrm{~m}$ in the Guaymas basin in the north to $3000 \mathrm{~m}$ at the mouth of the Gulf. The topography in the lower Gulf is very complex, with strong gradients across the shelf regions. On the east side, the shelf is wider and along the coastline there are many lagoons and estuaries. 


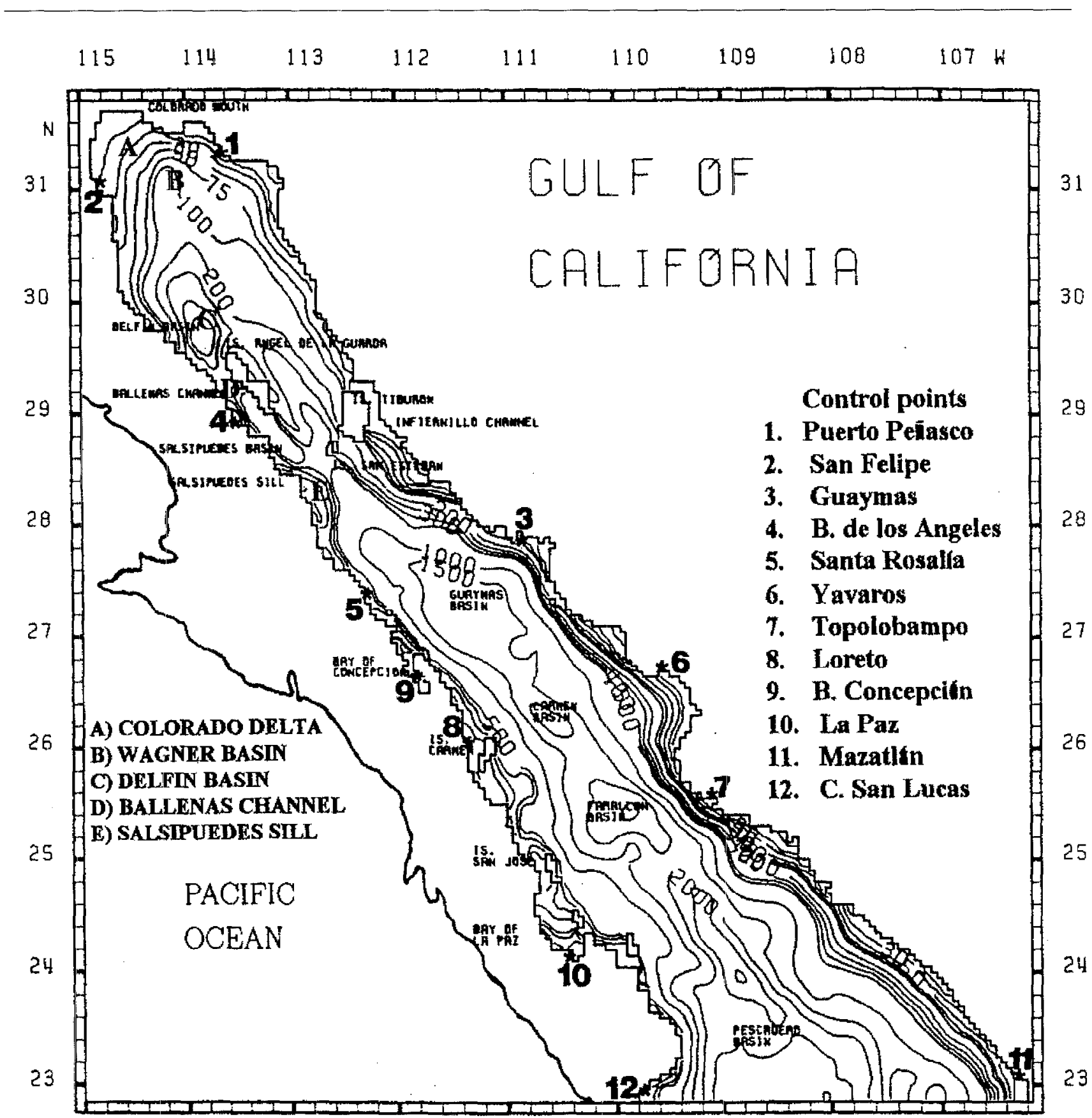

Figure 1. Geographical position and topography of the modelled region.

Different aspects of the tides in the Gulf of California have been mentioned in several works. Roden and Groves [41] reported their most impressive manifestation: A spring range of about $10 \mathrm{~m}$ and currents exceeding $3 \mathrm{~m} \mathrm{~s}^{-1}$. Hendershott and Speranza [29] proposed, at first, a picture of the virtual amphidrome traced in the central Gulf due to the propagation of the $M_{2}$ tide. From a modification of Taylor's theory [48], they could deduce a strong dissipation of tidal energy in the upper Gulf. Filloux [17], based on records of 10 to 60 days, made an energy budget and estimated the co-tidal and co-range maps of diurnal and semidiurnal tides. Through the application of a simple hydrodynamicalnumerical model, Stock [44] calculated tidal elevation and energetics. Special attention was given to resonance and dissipation. Dressler [14] simulated numerically the 
semidiurnal $M_{2}$ and the diurnal $K_{1}$ tides with the application of a vertically integrated two-dimensional model. Morales and Gutierrez [37] carried out an harmonic analysis of tidal records in the semidiurnal and diurnal bands. The residual flow of the $M_{2}$ tide was estimated by Quiros et al. [40]. The previously mentioned strong tidal flow produces internal waves, as reported by $\mathrm{Fu}$ and Holt [20]. They estimated that $10 \%$ of the semidiurnal tidal energy is dissipated in this way.

In this work, special emphasis is given to the calculation of residual currents in order to find the principal mechanisms by which they are produced. We also estimate the energy budgets of $M_{2}$ and $S_{2}$ individually and when both constituents interact. To delimit regions with high content of tidal energy and of strong dissipation rates, horizontal distributions of kinetic energy and of bottom dissipation rates were also estimated. The calculation of energy budgets allows the estimation of the periods of resonance in the Gulf. Other parameters, such as sea-surface elevation, tidal currents and eulerian residual flow, were also determinated.

\section{MATERIALS AND METHODS}

\subsection{Seiches}

Calculations of the Form number defined as $F=$ $\left(O_{1}+K_{1}\right) /\left(S_{2}+M_{2}\right)$ [13], where $O_{1}$ and $K_{1}$ are the amplitudes of the principal diurnal tides and $M_{2}$ and $S_{2}$ of the semi-diurnal, reveal that on the west side of the central Gulf, tides are predominantly of diurnal type $(F \geq 3.0)[6,37]$. In the northernmost part $F \leq 0.25$, semi-diurnal tides are the dominating signal. In the remainder of the Gulf, the tides are of mixed type $(0.25 \leq F \leq 3.0)$. In table 1 ; amplitude, phase and period of the seven most important tidal components $\left(M_{2}, S_{2}, K_{2}, N_{2}, K_{1}, P_{1}\right.$ el $\left.O_{1}\right)$ are given for several locations. This data set was taken from the Tabla de Prediccion de Mareas UNAM [47]. The stations are arranged from south to north. It is immediately apparent that the amplitudes of semi-diumal tides initially decrease to the north as far as Santa Rosalia, and are then strongly amplified in the northern Gulf. Since resonance is the amplified response of a basin to periodic forcing, this fact suggests then, the existence of a natural period of resonance in or near the semi-diurnal band. A first attempt [41] to locate the position of this natural period of resonance consisted in calculating the factor of amplification and the lag of tides in the semidiurnal band. The former is the ratio of the amplitude in the northernmost point (Puerto Peñasco) to the amplitude at the Gulf entrance (Cabo San Lucas); the latter is the phase difference between the same locations. The $\mathrm{N}_{2}$ tide, which has the longest period, undergoes the greatest amplification. Therefore, the resonance period probably coincides with or falls near to that of the $\mathrm{N}_{2}$ $(12.6583 \mathrm{~h})$. Another simple method is to suppose the

Table I. Amplitude (A) in $\mathrm{cm}$ and phase (P) in degrees of the principal tides in the Gulf of California. The periods in hours are also given. Data taken from Tabla de Mareas UNAM (Mexico), (1985).

\begin{tabular}{|c|c|c|c|c|c|c|c|c|c|c|c|c|c|c|}
\hline \multirow{3}{*}{$\frac{\text { Tide }}{\text { Period }(\mathrm{h})}$} & \multicolumn{2}{|c|}{$K_{2}$} & \multicolumn{2}{|c|}{$S_{2}$} & \multicolumn{2}{|c|}{$M_{2}$} & \multicolumn{2}{|c|}{$\mathrm{N}_{2}$} & \multicolumn{2}{|c|}{$K_{1}$} & \multicolumn{2}{|c|}{$P_{1}$} & \multicolumn{2}{|c|}{$o_{1}$} \\
\hline & \multicolumn{2}{|c|}{11.9672} & \multicolumn{2}{|c|}{12.00} & \multicolumn{2}{|c|}{12.4206} & \multicolumn{2}{|c|}{12.6583} & \multicolumn{2}{|c|}{23.9345} & \multicolumn{2}{|c|}{24.0659} & \multicolumn{2}{|c|}{25.8193} \\
\hline & A & $\mathrm{P}$ & A & $\mathrm{P}$ & A & $\mathrm{P}$ & A & $P$ & A & $P$ & A & $\mathrm{P}$ & A & $\mathrm{P}$ \\
\hline Cabo San Lucas & & 101 & 23.7 & 101 & 36.4 & 94 & 9.3 & 89 & 22.5 & 183 & 7.4 & 182 & 14.8 & 173 \\
\hline Mazatlan & 6.4 & 102 & 24.2 & 102 & 34.9 & 99 & 8.1 & 94 & 20.1 & 178 & 6.7 & 174 & 13.9 & 165 \\
\hline $\mathrm{La} \mathrm{Pa} \angle$ & 5.9 & 118 & 17.9 & 122 & 23.9 & 117 & 5.0 & 114 & 25.0 & 189 & 8.1 & 189 & 17.1 & 179 \\
\hline Topolobampo & 6.8 & 143 & 21.2 & 144 & 30.0 & 141 & 6.5 & 144 & 25.6 & 193 & 8.7 & 196 & 17.4 & 180 \\
\hline Loreto & 6.5 & 115 & 13.1 & 115 & 15.0 & 115 & 3.1 & 119 & 26.0 & 184 & 8.6 & 183 & 19.0 & 172 \\
\hline Yavaros & 5.5 & 145 & 15.7 & 143 & 22.1 & 147 & 5.5 & 151 & 25.7 & 190 & 8.5 & 189 & 17.8 & 174 \\
\hline Santa Rosalía & & & 5.3 & 140 & 5.8 & 191 & & & 30.1 & 183 & & & 20.1 & 171 \\
\hline Guaymas & 3.5 & 132 & 10.6 & 137 & 13.6 & 155 & 3.6 & 169 & 27.9 & 179 & 9.3 & 176 & 18.6 & 170 \\
\hline B. de los Angeles & 9.2 & 282 & 33.9 & 281 & 65.8 & 266 & 12.8 & 258 & 46.1 & 205 & 15.3 & 203 & 22.8 & 174 \\
\hline San Felipe & & & 96.8 & 277 & 165.2 & 268 & & & 40.0 & 189 & & & 24.5 & 177 \\
\hline Puerto Peñasco & 25.2 & 273 & 94.5 & 269 & 157.2 & 262 & 40.2 & 250 & 43.1 & 186 & 13.5 & 181 & 27.7 & 170 \\
\hline
\end{tabular}


Gulf to have a perfect rectangular form. The theory of seiches in channels of this geometrical form has been treated in detail by Defant [11] and Gill [23]. The formula $\tau=2 L /[n+1 / 2) \sqrt{ }(g H)]$ allows the estimation of the natural periods of resonance. With $L \approx 1000 \mathrm{~km}$ as the approximated length, $\mathrm{H}=650 \mathrm{~m}$ the mean depth, $\mathrm{n}=0$ (fundamental quarter wavelength oscillation) and $g=9.81 \mathrm{~m} \mathrm{~s}^{-1}$ the gravitational acceleration, results for the pcriod of resonance $\tau$ a value of 13.9 hours. This rough estimate is in agreement with the previous result, $\tau \geq N_{2}$ period.

Godin [24] mentions a modified formula to calculate the period of resonance, including friction

$\left[\tau_{f}=32 \pi \tau /\left(32 \pi-r_{1}^{2} \tau^{2}\right)\right]$

$r_{1}=3.9 \times 10^{-5}$ is the linear friction coefficient and $\tau$ is, as before, the natural period of resonance without consideration of friction. From this formula, a value of $\tau_{f} \approx 14.4 \mathrm{~h}$ is obtained. Filloux [17] reported for $\tau$ a value of $13.3 \mathrm{~h}$. Following a method developed by Garret and Munk [22], in which amplitudes and phases in and outside the Gulf are used, Stock [44] concludes that the period of resonance lies in the range $13.5 \mathrm{~h} \leq \tau \leq 15 \mathrm{~h}$. Applying a simplified numerical model to study the changes in the factor of amplification by varying the driving frequency at the Gulf entrance, he found two noticeable peaks; at the period $\tau \approx 13.9 \mathrm{~h}$ and at $\tau_{1} \approx 6 \mathrm{~h}$. The first of these peaks corresponds to the fundamental quarter-wavelength and the second to the three-quarter wavelength resonance of the Gulf. With the application of a vertically integrated numerical model and considering a nodal line at the Gulf entrance, Dressler [14], obtained for $\tau$ a value of $14.9 \mathrm{~h}$. Another experiment in which the Gulf was hypothetically completely closed revealed also a seiche in the Farallon basin with a period of $1.92 \mathrm{~h}$. Applying the iterative method of Lanczos, Gaviño [21] calculated the free modes and their corresponding energy flux in the Gulf of California. He obtained the periods of resonance of 11.7 and $5.37 \mathrm{~h}$. The consideration of friction would increase these values. An interesting result of his calculation is the accumulation of phase lines south of the midriff islands.

Although all estimates of the fundamental mode of resonance lie in the semi-diurnal band, there is a significant spreading of the values. Since any periodic forcing in the semi-diurnal band plays an important role in the dynamic of the Gulf, it is worthwhile to make an effort to calculate more accurately the principal periods of resonance.

\subsection{Hydrodynamical-numerical modelling of tides}

Tides in the Gulf of California arise essentially as a co-oscillation with the tides of the Pacific Ocean (direct gravitational forcing is ignored). They can be described by the vertically integrated equation of motion of Navier- Stokes and the equation of continuity. The integration takes place incorporating the kinematic boundary conditions.

Although the relatively small length and the channel form of the Gulf of California suggest the application of Cartesian coordinates (one of them parallel to the Gulf), it was decided to work with the real geographical orientation and to use spherical coordinates. This choice simplifies the selection of tidal data for the boundary conditions, since the line joining the towns Mazatlan and Cabo San Lucas coincides with the open boundary selected in this work. Moreover, in the case of baroclinic simulations, the positions of temperature and salinity data are always given in spherical coordinates. The topography (see figure 1) was digitized with a mesh spacing of $0.1^{\circ}$ or $6^{\prime}$. This means a mesh spacing $\Delta L$ between $10243 \mathrm{~m}$ at the Gulf entrance and $9450 \mathrm{~m}$ at the northernmost point.

The stability criterion of Courant-Friedrich-Lewy

$\Delta L \leq \frac{\Delta L_{\min }}{\sqrt{\left(2 g H_{\max }\right)}}$

where $\Delta L_{\min }=9450 \mathrm{~m}$ and $H_{\max }=3176 \mathrm{~m}$ limits the time step, in the explicit case, to the condition $\Delta t \leq 37.8 \mathrm{~s}$. The coefficient of friction was varied in the range $.0025 \leq r \leq .0035$. For the coefficient of eddy viscosity, the variable form $A_{H}=A_{k} \Delta L H$ was chosen (see [42]), with $A_{k}$ as a proportionality constant. All calculations were carried out from the initial conditions $U=V=\zeta=0$, where $U$ is the transport in eastwest direction and $V$ in the north-south. The boundary condition for the coast is that the normal component of the transport $V$ must vanish i.e.,

$V \cdot n=0$,

where $n$ is a unit vector normal to the coast. The second condition is that, for open boundaries

$\frac{\partial V_{n}}{\partial x_{n}}=0$,

where the components of the transport $V_{n}$ and the coordinate $x_{n}$ are perpendicular to the boundary. At 
closed boundaries, a semi-slip condition was applied to the component of the velocity parallel to the coast. At the open boundary, the sea surface elevation $\zeta$ is given in the form $\zeta(t)=A \cos (\omega t-\Phi)$, where $\omega$ is the angular frequency of the tidal component. $A$ and $\Phi$ are the observed amplitudes and phases. In this work, the limits of the line extending along the open boundary coincide with the towns Cabo San Lucas on the peninsula of Baja California and Mazatlán on the mainland. The values of amplitude and phase observed at these sites were then linearly interpolated for all boundary points. At the bottom the quadratic friction form of Taylor

$\tau_{b}=\frac{r(u, v)}{H+\zeta} \sqrt{\left(u^{2}+v^{2}\right)}$

is used.

\subsection{Two-dimensional semi-implicit model}

The explicit method of finite difference, developed by Hansen [25] for the solution of the non-linear partial differential equations of hydrodynamics by prescribing initial and boundary conditions, has demonstrated its efficiency in a great number of simulations of tides, storm surges and problems of the general circulation $[4,10,14$, $16,19,46]$. This algorithm, also called the HN-method, is used extensively and has been described in detail in several works [45]. However, the selection of an implicit scheme, which is not bound by the CFL restriction, is more suitable for the Gulf of California, where depths varying between 10 and $3200 \mathrm{~m}$ are found. The smallest gravity waves resolved by the applied grid have a period (cut-off period) $T c=2 \Delta L / c$, where $c=\sqrt{(g H)}$ is the phase velocity. For the shallow northern part, with $\Delta L=10000 \mathrm{~m}$ and $h \approx 100 \mathrm{~m}$, then $T c \approx 638 \mathrm{~s}$, whereas the global time step after the CFL restriction is $38 \mathrm{~s}$. This mismatch was resolved with the application of a semi-implicit scheme proposed by Backhaus [2]. The main features of the model are described in several works $[2,6,15,34]$. This two-dimensional scheme is neutral in reference to the amplitude, i.e. the signal is not dampened. However, a characteristic of implicit schemes is the phase error when the time step significantly exceeds the CFL condition. This phase error is given by

$\sin (\Delta \Phi)=2 \sqrt{g H} \frac{\Delta t}{\Delta x} \sin \left(\frac{\kappa}{2} \Delta x\right)$,

where, $\kappa=2 \pi / \lambda$ is the wave number and $\lambda$ the wavelength. For long waves, however, the error is relatively small ( $\sin \kappa \Delta x / 2=\kappa \Delta x / 2$ ). To test this, severals runs were performed with time steps varying between values of cut-off periods of shallow and deep regions. The horizontal coefficient of eddy viscosity $A_{H}$ was used with $A_{k}=0.0002$ in all calculations as indicated above. The coefficient of friction with a constant value $r=0.0035$ produced the best global results. The modelled area comprises a matrix of $90 \times 89$ points, with about $1 / 3$ of them as wet points.

\section{RESULTS}

To reach a high degree of stationarity, in all experiments the $M_{2}$ tide was simulated during 100 periods. In order to investigate how the selection of time step affects the values of sea-surface elevation, phase and tidal currents, a series of numerical experiments were carried out. For the time steps $\Delta t_{1}=174.7 \mathrm{~s}, \Delta t_{2}=349.3 \mathrm{~s}$ and $\Delta t_{3}=698.7 \mathrm{~s}$, no major changes occurred, even though the greatest time step is four times larger than the smallest. Results for $\Delta t=698.7 \mathrm{~s}$, are given in table II. Amplitude in centimetres and phase in degrees (in reference to Greenwich) are also shown. Phase errors for the $M_{2}$ tide remain reasonably small for this time step. The calculated amplitude values agree quite well with those reported in prediction tables. The small value at Santa Rosalía and the high one at Puerto Peñasco are reproduced acceptably.

Large differences in phase are found at places such as La Paz, Yavaros and Topolobampo. These towns are located in shallow bays, which are not well resolved by the mesh used in the model. Therefore, the phase delay is not satisfactorily simulated. This fact is supported by the observed phase at Yavaros, as given by Filloux [17] which was measured at the same location but in the open sea. Here, the agreement with the calculated results is good. For a global view, the co-tidal (degrees) and co-range $(\mathrm{cm})$ lines are shown in figure 2 . The distribution and form of the isolines coincide with the numerical results of Dressler [14] and particularly with the measurements of Filloux [17]. The amphidrome traced by the $M_{2}$ tide is displaced to the west, and becomes almost virtual. Several theoretical studies [7, 29] showed that dissipation of tidal energy is responsable for this kind of shift of amphidromic points. Consequently, it is of interest to locate zones of intense flow and to investigate the strength of the dissipation rates of energy. From previous work $[1,6]$, it is known that there are three 
Table II. Amplitude $(\Lambda)$ in centimetres and phase (P) in degree of the $M_{2}$ tide for several time steps. The calculations were carried out with the two-dimensional semi-implicit model.

\begin{tabular}{|c|c|c|c|c|c|c|c|c|}
\hline & \multicolumn{2}{|c|}{$\begin{array}{l}\text { Prediction } \\
\text { tables }\end{array}$} & \multicolumn{2}{|c|}{$\Delta \mathrm{t}=698.6 \mathrm{~s}$} & \multicolumn{2}{|c|}{$\begin{array}{c}\text { Dressler } \\
\text { Explicit model }\end{array}$} & \multicolumn{2}{|c|}{$\begin{array}{c}\text { Filoux } \\
\text { Measurements }\end{array}$} \\
\hline & A & $\mathrm{P}$ & A & $\mathrm{P}$ & A & $\mathrm{P}$ & A & $P$ \\
\hline La Paz & 23.9 & 117 & 26.8 & 96 & 27.0 & 94 & & \\
\hline Topolobampo & 30.0 & 141 & 27.6 & 105 & 26.0 & 101 & & \\
\hline Loreto & 15.0 & 115 & 15.4 & 107 & 14.0 & 110 & 15.0 & 115 \\
\hline Yavaros & 22.1 & 147 & 21.2 & 117 & 23.0 & 143 & 20.0 & 123 \\
\hline Santa Rosalía & 6.8 & 191 & 6.8 & 181 & 4.2 & 169 & 7.2 & 193 \\
\hline Guaymas & 13.6 & 155 & 13.1 & 150 & 16.0 & 172 & 13.0 & 159 \\
\hline B.de los Angeles & 65.8 & 266 & 72.6 & 265 & 82.0 & 277 & & \\
\hline San Felipe & 165.2 & 268 & 171 & 270 & 171.0 & 283 & & \\
\hline Puerto Peñasco & 157.2 & 262 & 160.0 & 261 & 173.0 & 274 & & \\
\hline
\end{tabular}

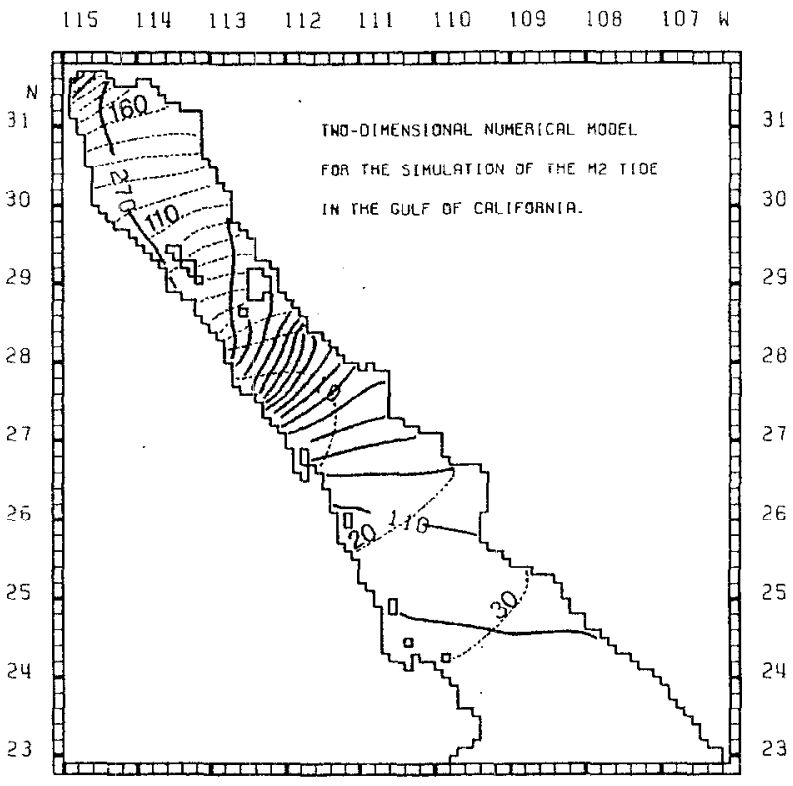

Figure 2. Co-tidal (thick, degrees) and co-range (broken, $\mathrm{cm}$ ) lines using a time step of $\Delta t=698.7 \mathrm{~s}$. The total time simulated was $100 M_{2}$ periods.

regions where dissipation rates of tidal energy through bottom friction are large; on the northern side of the Ballenas Channel, over the Salsipuedes Sill and in the Colorado Delta. The tidal flow and dissipation rates are discussed in the following sections.

Since we are more interested in the study of flow-related parameters, we only mention certain characteristics found in the analysis of time series of sea-surface elevation.
Sea-level variations at the several control points exhibit a marked diversity in behaviour (for details see [6]). At Puerto Peñasco, the time series is characterized by high amplitudes and is nearly sinusoidal. In contrast, at Yavaros the amplitudes are small and the crest of the wave is flat. An interesting case is the sea-level variation in Concepcion Bay, where the high harmonic $M_{4}$ has almost the same amplitude as the $M_{2}$. Although this region is represented in the model with only a few points, the length of the bay suggests a period of resonance near to six hours, which would explain this qualitative result. Unfortunately, no data exists for this area. The Fourier transformation of time series of points situated in the northern Gulf always showed high harmonics. The $M_{4}$ here reached amplitudes between 1 and $3 \mathrm{~cm}$.

There are several reasons to investigate barotropically the principal features of tidal currents in the Gulf of California. Hydrographic measurements in the northern part of the Gulf reveal that winter cooling leads to an homogenization of the water column. Consequently, the processes have, at least partially, a barotropic character. Recent studies $[9,32]$ demonstrated that the Gulf of California exhibits a net gain of heat from the atmosphere. Although the baroclinic flow is surely the dominant process of heat transport southwards, barotropic mechanisms may also be significant due to both the intensity of tidal currents and a complex topography. Another aspect is provided by analysis of the flow structure in the area of the Colorado River Delta in this global simulation of the tides in the Gulf of California. It is known that in this shallow area, tidal currents are strong. Furthermore, satellite images 
[7] demonstrate that the transport of sediments in this area is very intense.

When the flow was maximum southwards, the strongest velocities associated with the $M_{2}$ tide were found close to the mouth of the Colorado River $\left(83 \mathrm{~cm} \mathrm{~s}^{-1}\right.$ ) (see figure 3). Over the Salsipuedes Sill, velocities reach values of $80 \mathrm{~cm} \mathrm{~s}^{-1}$. The cross-Gulf velocities are small and therefore the flow occurs mainly along the length of the Gulf. In the southern region, the velocities reach values of only $5 \mathrm{~cm} \mathrm{~s}^{-1}$. From the central Gulf to the north, they increase rapidly. Another interesting aspect is the strength $\left(60 \mathrm{~cm} \mathrm{~s}^{-1}\right)$ of the velocities in the northern part of the Ballenas Channel (for geographical orientation see figure 1 ), and between the islands San Esteban and Tiburon $\left(80 \mathrm{~cm} \mathrm{~s}^{-1}\right)$. The zone of strong currents in the delta of the Colorado River agrees with the estimated region of well mixed conditions [1]. It is also of interest to mention that the areas of maximum flow in the Ballenas Channel and over the Salsipuedes Sill agree quite well with the places where internal waves originate [20].

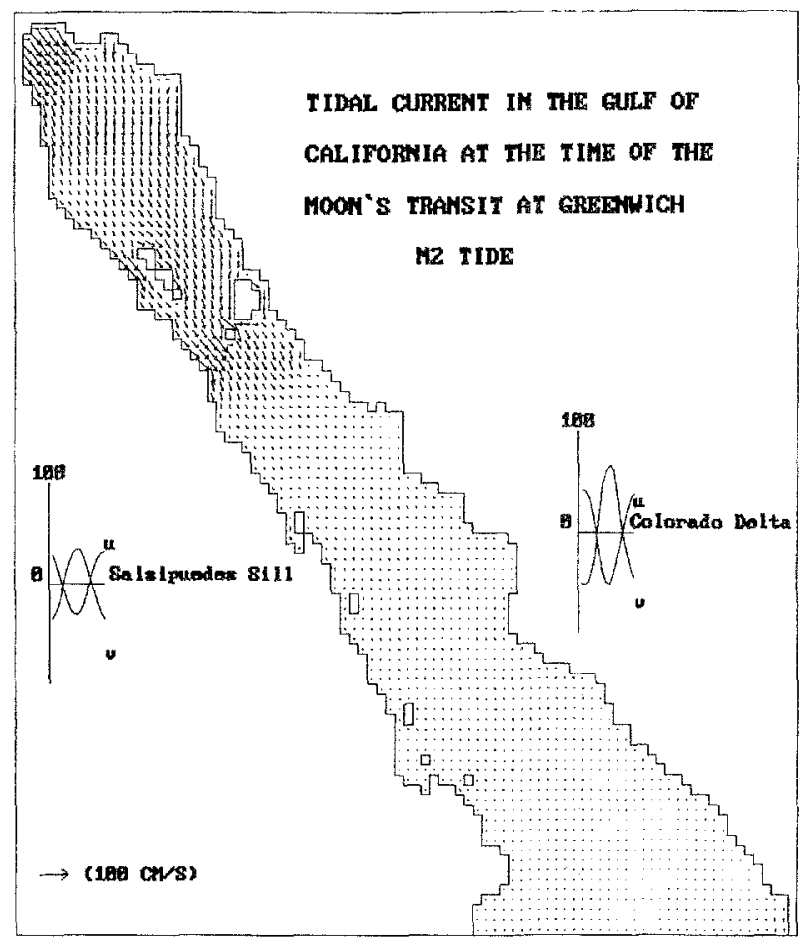

Figure 3. Velocities in $\mathrm{cm} \mathrm{s}^{-1}$ at the time of the moon's transit at Greenwich. Time series of $u$ and $v$ for points in the Salsipuedes Sill and in the Colorado Delta are also given.
Residual currents were calculated in different ways and following methods applied in other works $[18,27,49]$. Since residuals of semi-diurnal tides are small in the lower Gulf, results are presented only for the northem half. The eulerian residual current defined by

$u_{e}=\frac{1}{T} \int_{T} u d t$

was calculated with and without the consideration of the non-linear terms. In figure $4 a$, the non-linear terms were included and calculated with a vector unstream method $[26,30]$. Clearly, four gyres can be distinguished. The most vigorous one, with cyclonic circulation and with residual currents of about $20 \mathrm{~cm} \mathrm{~s}^{-1}$ extends over the north and south sides of the Salsipuedes Sill (gyre 1). It is known that mixing processes in the Ballenas Channel [38] and in general in the vicinity of the islands are very intense [43]. In this region an anomaly is observed; water in the surface layer is colder than the surrounding zones and warmer in the deep layers. Although baroclinic flow dominates in the process of water exchange between this zone and the lower Gulf, the intensity of this barotropically-induced gyre indicates that it should also play an important role in this exchange of water masses. Between the islands Tiburon and Angel de la Guarda, another gyre with anticyclonic circulation and with maximum currents of $15 \mathrm{~cm} \mathrm{~s}^{-1}$ is found (gyre 2). Around the Delfin basin, the circulation is anticyclonic with velocities of about $10 \mathrm{~cm} \mathrm{~s}^{-1}$ (gyre 3). In the north part of the Gulf around the Wagner basin, an anticyclonic flow $\left(4 \mathrm{~cm} \mathrm{~s}^{-1}\right.$ ) can be seen (gyre 4). Eliminating the nonlinear terms in the calculations, the results are now quite different for the eulerian residual current (see figure $4 b$ ). Gyres 1,2, and 3 disappear almost completly, while gyre 4 has been substantially modified. Observe that in this different scale of the velocity vectors, another gyre with cyclonic circulation $\left(3 \mathrm{~cm} \mathrm{~s}^{-1}\right)$ comes into view close to the northwest coast of the Gulf (gyre 5). The residual flow structure 4 evidently results from bottom friction effects. Gyre 5 is generated topographically by induction of vorticity around the Wagner basin. Since in the areas of gyres 1, 2, and 3 the tidal flow is very intense, advection of vorticity produced at the points of major topographic change seems from these calculations to be the principal mechanism for the generation of residual currents. Zimmerman [52] derived an equation for the perturbation vorticity. By averaging this equation over a tidal cycle, Quiroz et al. [40] estimated that advection of perturbation vorticity by the unperturbated tidal velocity and vortex stretching are the dominant terms in the 

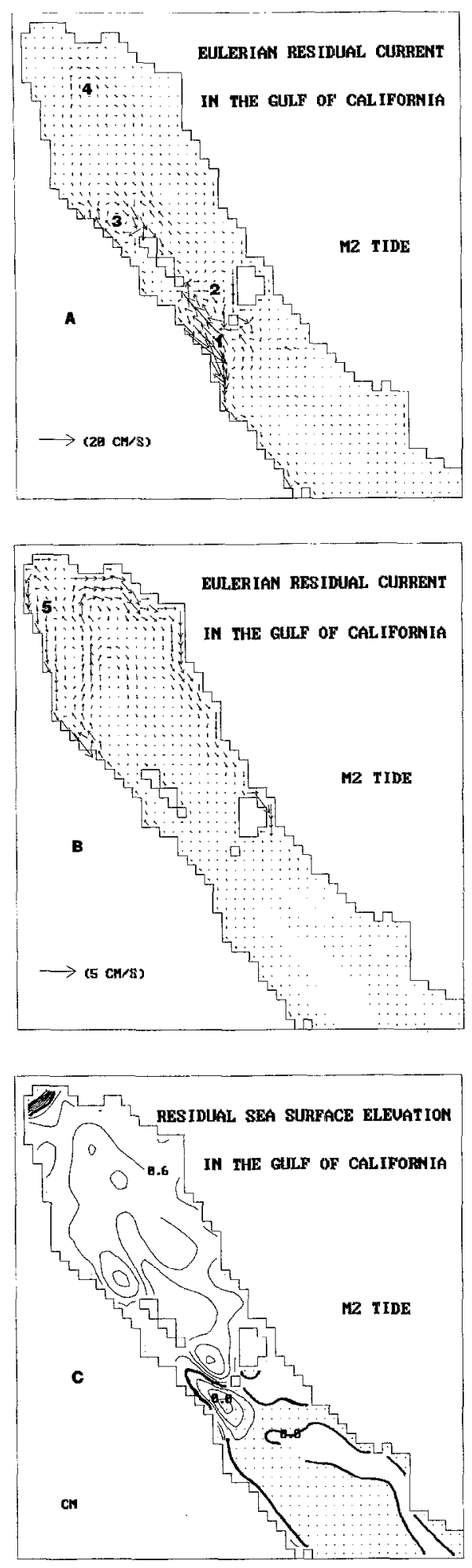

Figure 4. (a) Eulerian residual current $u_{e}$ of the $M_{2}$ tide. (b) $u_{e}$ with no consideration of the non-linear terms. (c) Residual sea-surface elevation. budget of residual perturbation vorticity in the Gulf of California. This is in agreement with our results. The size of these gyres also becomes visible in a picture of the residual sea-surface elevation (figure $4 c$ ). Values of $-0.6 \mathrm{~cm}$ (gyre 1), $+0.8 \mathrm{~cm}$ (gyre 2), $+1.0 \mathrm{~cm}$ (gyre 3), $+0.8 \mathrm{~cm}$ (gyre 4 ) and of $-2.0 \mathrm{~cm}$ in the Colorado Delta were obtained.

The Lagrangian residual current defined by the equation (4) according to Maier-Reimer [33] was also calculated for the $M_{2}$ tide.

$u_{L}=\frac{\int_{T} U d t}{\int_{T} H d t}$

In the equation, $U$ is the transport, $H$ the depth, $t$ the time and $T$ the period of integration. Velocity values are slightly stronger than the eulerian residual current depicted in $(4 a)$, but in general $u e \approx u_{L}$ and the pattern is similar. For this reason, it is not shown.

Since the tidal flow in the Gulf is to a large extent rectilinear, the Stokes velocity. $u_{s}$ can be defined by

$u_{s}=\frac{1}{H T} \int_{T} u \zeta d t$

In this case, the transport velocity $u_{t}$ is nearly equal to the Lagrangian velocity [39], i.e. $u_{L} \approx u_{t}=u_{e}+u_{s}$. Since our results show that $u_{L} \approx u_{e}$, it can be argued that contributions due to Stokes velocity are small.

Identical simulations to that of the $M_{2}$ tide were performed for the $S_{2}$ and $K_{1}$. The $S_{2}$ tide has a behaviour similar to the $M_{2}$ (figure .5). In the area of Santa Rosalia, the amplitudes are of only a few centimetres, but in the Colorado River Delta, amplitudes of $125 \mathrm{~cm}$ are found. A simple inspection of figure 5 reveals an agreement with the observed values given in table $I$. Since the position of the first amphidromic point in relation to the closed side depends on the wavelength, the amphidrome of the $S_{2}$ is located slightly to the north of that of the $M_{2}$. Although there is obviously amplification of the signal, the amplitudes do not reach the values of the $M_{2}$. Observe that the co-tidal lines converge to a point located close to the coast. The western shift of the amphidromic point is not as strong as in the case of the $M_{2}$ tide. This is an indication of smaller dissipation rates of tidal energy.

The propagation of diurnal tides in the Gulf of California is of a more simple nature. This is documented here with the $K_{1}$ tide. The amplitudes increase monotonically to the north from $20 \mathrm{~cm}$ at the Gulf entrance to $45 \mathrm{~cm}$ in the area of the Colorado Delta. Practically the whole 


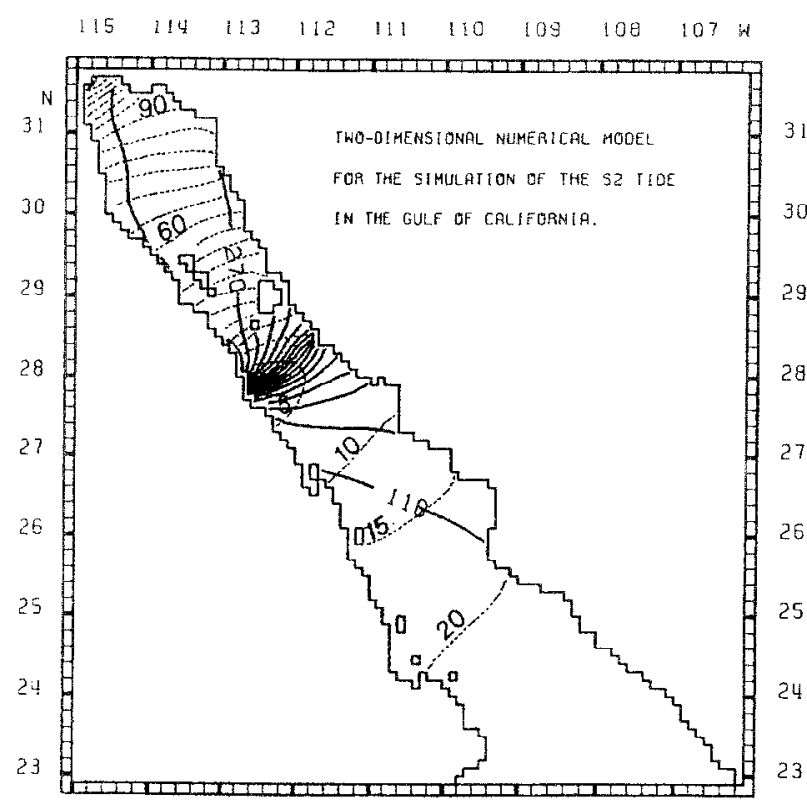

Figure 5. Co-tidal and co-range lines of the semi-diurnal tide $S_{2}$.

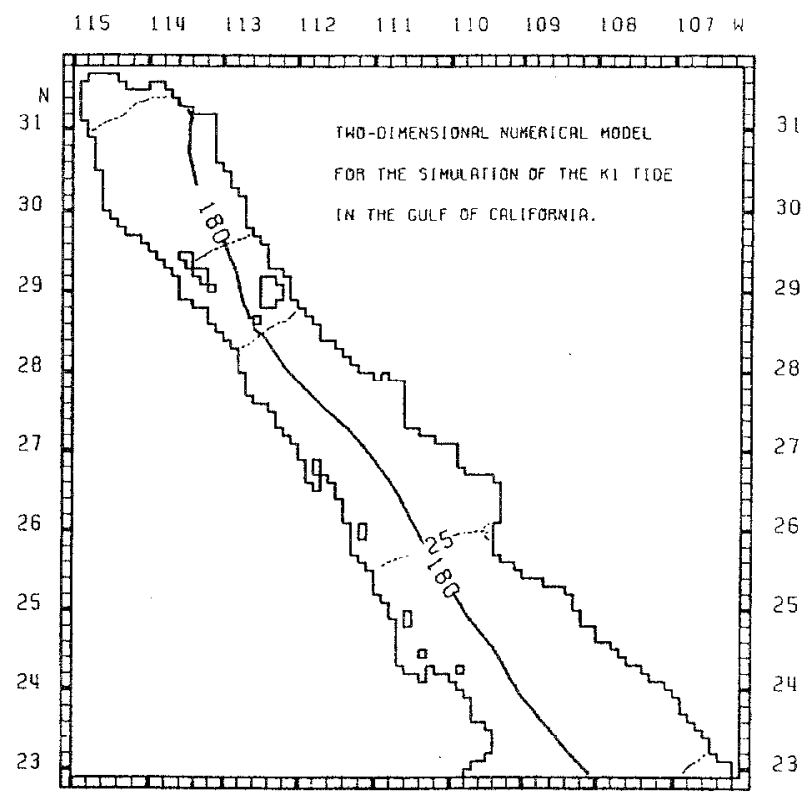

Figure 6. Co-tidal and co-range lines of the diurnal tide $K_{1}$.

Gulf is in phase, since the co-tidal lines extend along the Gulf (figure 6). This suggests a behaviour similar to a standing wave, in which most of the energy flowing into the Gulf is radiated back to the Pacific Ocean.
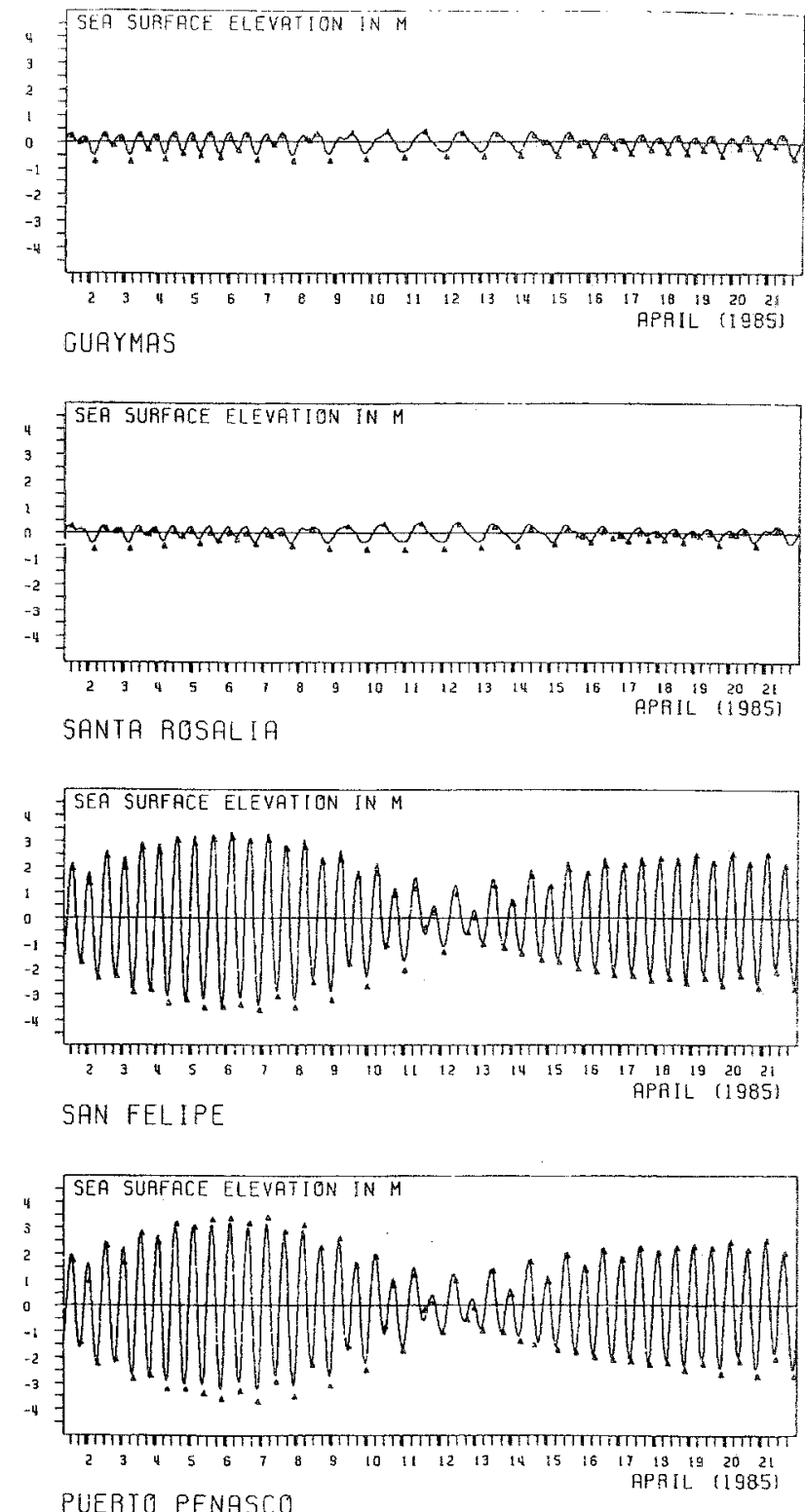

Figure 7. Computed (solid lines) and observed (predicted on the basis of observation) (triangles) sea-surface elevations at representative locations. The simulated days correspond to the period of time between the 1 and 21 April 1985 .

The three partial tides described above, i.e. the $M_{2}$, $S_{2}$ and the $K_{1}$, are the most important in the tidal dynamic of the Gulf. At spring tides, the sum of amplitudes and velocities produced by the constructive interference of the $M_{2}$ and the $S_{2}$ tides is particularly large, and plays a decisive role in the generation of other oceanographical phenomena such as the production 
of internal waves [20] and mixing processes. In order to probe the interaction of the seven most important partial tides $\left(M_{2}, S_{2}, N_{2}, K_{1}, P_{1}, O_{1}\right)$, a run simulating tides for an actual period of time was carried out. The period of time simulated was from 1 to 21 April 1985. The amplitudes and phases were corrected according to the astronomical arguments reported in Tafel der Astronomischen Argumente $V_{0}+\nu$ und der Korrektionen [12]. In figure 7, several time series at different control points in the Gulf are shown. Although the values obtained from prediction tables (triangles) are based on more harmonic constants, the model results (continuous line) agree well with the reported amplitudes and phases. The model correctly reproduced high amplitudes at spring tides and for periods of low water (see for example Puerto Peñasco). The especially complex behaviour of the sea level at Guaymas was satisfactory simulated. However, small general differences in amplitude are observed. This is probably due to the fact that longperiod tides were not considered. It is also interesting to mention the intensity of the currents produced by the seven tidal constituents considered in this experiment. In the region of the Colorado River Delta, velocities of $140-160 \mathrm{~cm} \mathrm{~s}^{-1}$ were calculated. These values give an idea of the strength of mixing processes. Indeed, satellite imagery shows that at spring tides, a large cloud of suspended sediment originates in this area by bottom friction induced turbulence. Over the Salsipuedes Sill, values of the same order were found. Estimates of the parameter $\log \left(h / u^{3}\right)$, a criterion for determining the position of fronts, predict completly mixed conditions for most of the area of the Colorado River Delta [1]. However, the time series of Puerto Peñasco and San Felipe shown in figure 7 exhibit at neap tides amplitudes of only $\approx 50 \mathrm{~cm}$, and consequently the tidal currents should be much smaller. This may lead to periods of stratification which, as the time of spring tides approaches, is again eroded. It would undoubtedly be of interest to investigate this process.

\section{Energy budget}

After the model was appropriately adjusted to reproduce correctly the tides in the Gulf of California, as described in the preceding section, a new series of numerical experiments were carried out to calculate energy budgets. It was of special interest to determine the total energy stored in the Gulf associated with the tidal constituents $M_{2}$ and $S_{2}$, as well as the total dissipated energy, and to obtain an idea of the spatial distribution of parameters relating for example, to kinetic energy and rates of energy dissipation by bottom friction. It is generally accepted that the total world dissipation of tidal energy in the sea causes a deceleration of the angular velocity of the earth. However, the locally resulting torque due to dissipation can have an accelerating character [5]. Energy dissipation occurs principally in shelf regions and in shallow adjacent seas. This loss is compensated by the energy flow to the oceans caused by the tidegenerating forces. Through tidal currents, this energy is again transported to the shallow regions. An attempt is made here to determine the role played by the Gulf in this process.

The equation describing the energy relations is derived from the Navier-Stokes equation of motion and from the equation of continuity. The velocities are vertically averaged in the form

$u=\frac{1}{H} \int_{-H}^{\zeta} u_{f}(z) d z$

Detailed descriptions of the derivation of the energy equation are given by von Trepka [50], Zahel [51] and Mihardja [34]. The main steps are: the $u$-component is multiplied by $u H$, the $v$-component by $v H$ and the continuity equation by $g \zeta$. Through addition of the first two resulting equations and application of the third, the energy equation

$$
\begin{aligned}
& \frac{d\left(H\left(u^{2}+v^{2}\right) / 2\right)}{d t}+\frac{d\left(g \zeta^{2} / 2\right)}{d t} \\
& \quad+r\left(u^{2}+v^{2}\right)^{3 / 2}-A H\left(u \nabla_{H}^{2} u+v \nabla_{H}^{2} v\right) \\
& \quad+\frac{1}{R \cos \phi}\left(\frac{\partial(H u \zeta)}{\partial \lambda}+\frac{\partial(H v \zeta \cos \phi)}{\partial \phi}\right)=0
\end{aligned}
$$

is obtained. After integration over the whole surface of the Gulf $S$, the following individual terms constitute, then, the energy equation: the kinetic energy

$E k=\frac{1}{2} \int_{S} H\left(u^{2}+v^{2}\right) d S$,

the potential energy

$$
E p=\frac{1}{2} \int_{S} g \zeta^{2} d S
$$


rate of energy dissipation through bottom friction

$$
-E b=\frac{1}{2} \int_{S} r\left(u^{2}+v^{2}\right)^{3 / 2} d S,
$$

rate of energy dissipation through eddy viscocity

$$
E v=\int_{S} H A H\left(u \nabla_{H}^{2} u+v \nabla_{H}^{2} v\right) d S
$$

and the energy flow at the open boundary

$$
-E=\int_{S} \frac{1}{R \cos \phi}\left(\frac{\partial(H u \zeta)}{\partial \lambda}+\frac{\partial(H v \zeta \cos \phi)}{\partial \phi}\right) d S
$$

The total dissipated energy is defined as $E_{d}=E_{b}+E_{v}$. The tidal energy changes in periodic form, therefore, the mean value over a period $T_{0}$

$\bar{E}_{f}=\frac{1}{T_{0}} \int_{0}^{T_{0}} E_{i} d t$

does not change ( $E_{i}$ is some component of equation 7$)$. The energy equation can be expressed, then, in the form

$d \frac{\left(\bar{E}_{k}+\bar{E}_{p}\right)}{d t}=\bar{E}_{d}+\bar{E}_{f}=0$.

In the calculation of the energy budgets of the $M_{2}$ and $S_{2}$ tides, a total number of 100 periods were simulated. A high degree of stationarity was reached with this time of simulation. The oscillations approaching the convergence energy values were less than $1 \%$. The results of the computations are shown in the first two columns of table III. The mean kinetic energy $\bar{E}_{k}$ is of the same order as the mean potential energy $\bar{E}_{p}$. The dissipation of tidal energy due to eddy viscosity is about $1 / 2$ of the dissipated energy through bottom friction. The total dissipated energy by the $M_{2}$ tide is $3.44 \times 10^{\circ} \mathrm{J}$ $\mathrm{s}^{-1}$. This value is smaller than those published in other works. Filloux [17] mentioned the following estimates; Heiskanen [28] gives a value of $2.5 \times 10^{10}$, Miller [35] of $4.0 \times 10^{10}$ and Hendershott and Speranza [29] of 1 to $2 \times 10^{10}$. However, all these values are coarse estimates. On the basis of measurements, Filloux [17] obtained a value of $4.35 \times 10^{9}$ and Dressler [14] calculated a value of $4.15 \times 10^{9}$ with the application of a numerical model. In the same fashion, Argote et al. [1] calculated a value of $3.9 \times 10^{9}$. The total dissipated energy in the Gulf of California represents about $0.1 \%$ of that calculated for the world ocean [51].

The factor of resonance $Q$ is defined as the fraction of energy dissipated in a cycle, i.e. $Q=2 \pi N$, where $N$ is the number of cycles needed to dissipate the stored energy in the system. The total energy stored in the Gulf due to the $M_{2}$ tide $\bar{E}_{k}+\bar{E}=4.61 \times 10^{14}$ would be totally dissipated, at the rates computed in this work, in approximately three $M_{2}$ periods. The factor of resonance $Q$ takes, then, with $N=3$ the value of 18.8. Filloux [17], calculated for $Q$ a value of 13.2. Stock [44], applying a method developed by Garret and Munk [22], gives for $Q$ a range of variation $5 \leq Q \leq 10$ With the application of a numerical model, the same author obtained $11.1 \leq Q \leq 11.8$. In the same way, it was calculated that the energy stored by the $S_{2}$ tide would be dissipated in $N=4.16$ periods. In general, the energy parameters for this tide are almost an order smaller than those of the $M_{2}$. In figure 8 , time series of the energy parameters integrated over the whole Gulf are shown. The constant line represents the average value of energy inflow within a period. Compared with Filloux's measurements, these values are

Table III. Individual energy budget of the $\mathrm{M}_{2}$ and $\mathrm{S}_{2}$ tides averaged in a modulation period. Their linear sum is compared to the energy budget obtained in the case of simultaneous simulation.

\begin{tabular}{lcccc}
\hline & $\mathbf{M}_{2}$ & $\mathbf{S}_{2}$ & $\begin{array}{c}\text { Linear sum } \mathbf{M}_{\mathbf{2}} \\
+\mathbf{S}_{\mathbf{2}}\end{array}$ & $\begin{array}{c}\text { Simulation of } \mathbf{M}_{\mathbf{2}} \\
\text { and } \mathbf{S}_{\mathbf{2}}\end{array}$ \\
\hline Kinetic energy $(\mathrm{J})$ & $2.44 \times 10^{14}$ & $7.57 \times 10^{13}$ & $3.20 \times 10^{14}$ & $3.22 \times 10^{14}$ \\
Potential energy $(\mathbf{J})$ & $2.17 \times 10^{14}$ & $7.02 \times 10^{13}$ & $2.87 \times 10^{14}$ & $2.90 \times 10^{14}$ \\
Energy dissipation due to eddy viscocity $(\mathrm{J} / \mathrm{s})$ & $1.10 \times 10^{9}$ & $3.53 \times 10^{8}$ & $1.45 \times 10^{9}$ & $1.45 \times 10^{9}$ \\
Energy dissipation due to bottom friction $(\mathrm{J} / \mathrm{s})$ & $2.34 \times 10^{9}$ & $4.61 \times 10^{8}$ & $2.80 \times 10^{9}$ & $3.97 \times 10^{9}$ \\
Total dissipation of energy (J/s) & $3.44 \times 10^{9}$ & $8.13 \times 10^{8}$ & $4.25 \times 10^{9}$ & $5.42 \times 10^{9}$ \\
Energy inflow at the open boundary (J/s) & $3.18 \times 10^{9}$ & $8.15 \times 10^{8}$ & $4.29 \times 10^{9}$ & $5.48 \times 10^{9}$ \\
Energy difference between inflow and dissipation $(\mathrm{J} / \mathrm{s})$ & $0.04 \times 10^{9}$ & $0.02 \times 10^{8}$ & $0.04 \times 10^{9}$ & $0.06 \times 10^{9}$ \\
\hline
\end{tabular}



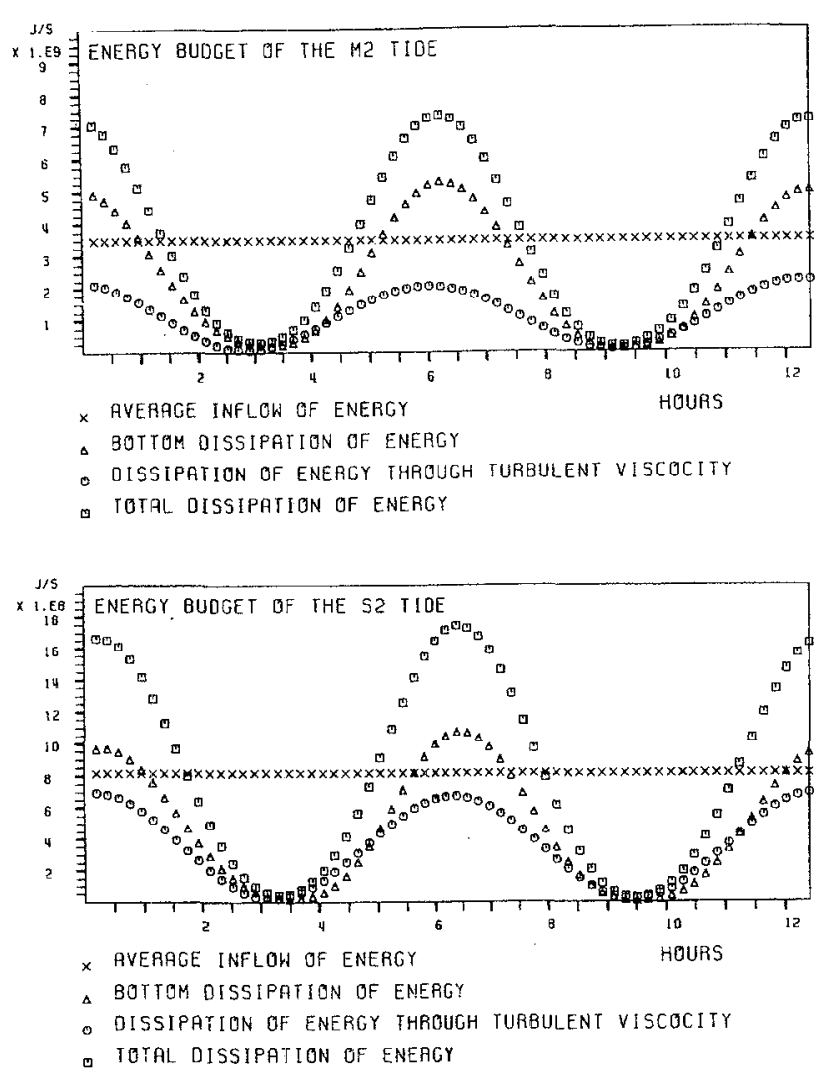

Figure 8. Time series of energy parameters of the $M_{2}$ and $S_{2}$ tides.

smaller. The reason for this difference could be the nonconsideration of baroclinic effects. As mentioned in the introduction, approximately $10 \%$ of the dissipation of energy occurs through internal waves. Other experiments, which included direct gravitational forcing, showed that the flow of energy to the Gulf $\left(\approx 0.08 \times 10^{9}\right)$ in this way is almost two orders smaller than the flow of energy at the open boundary. However, as this estimated value is only slightly larger than the convergence errors, it should be taken as a coarse approximation.

The geographical distribution of average rates of dissipation of tidal energy due to bottom friction is given in figure 9 for the $M_{2}$ and $S_{2}$ tides. The quantities refer to rates of energy dissipation per grid point. The average dissipated energy in the area of the Colorado mouth is of the same order as that dissipated in the remainder of the Gulf. Simple estimates indicate that the dissipated energy in a tidal period would increase the temperature of this area by about $.001^{\circ} \mathrm{C}$. Since the dissipation of tidal energy is concentrated in the vicinity of the closed end, the solution given by Hendershott and Speranza [29] can be applied to explain the observed amphidromic system of semi-diurnal tides in the Gulf of California. On the northern side of the Ballenas Channel and in the region of the Salsipuedes Sill, the dissipation is of considerable magnitude. In the southern region of the Gulf, it is insignificant. All these considerations are valid for $M_{2}$ and $S_{2}$ alike. Since the dissipation of energy is concentrated in these three areas, the selection of a constant friction coefficient does not markedly affect the results. The distribution of the vertically integrated kinetic energy is illustrated with the $M_{2}$ tide. As can be seen in figure 10, the calculated kinetic energy takes the largest values in Ballenas Channel and over the Salsipuedes Sill. Around the island Angel de la Guarda, it is of the same magnitude. These results agree with observations carried out in the Gulf showing that the tidal currents in these areas are especially strong. It is of interest to mention that this distribution of kinetic energy agrees quite well with the mean distribution of sea-surface temperature obtained from a series of satellite images [38], and with Paden's finding that the sea-surface temperature is associated with vertical mixing processes caused by tidal currents. Along the northern coast and in the southern part of the Gulf, the kinetic energy is small. The low values in the area of the Colorado River Delta can be explained by the shallowness of that region. A plot of the kinetic energy per unit of volume would give high values for this area.

It has already been pointed out that a regional dissipation does not necessarily mean a contribution to deceleration of the earth's rotation. To test this, the sign of the torque produced by the friction force must be determined. The mean torque with respect to the axis of the earth's rotation is given by [5]

$\bar{M}=\int_{S} r R \cos \phi u\left(u^{2}+v^{2}\right)^{3 / 2} d S$

and the change of the rotational energy is defined as

$\bar{E} \operatorname{rot}=\Omega \bar{M}$.

$\bar{M}=-6.57 \times 10^{10} \mathrm{~J}$ was obtained in this way and therefore, $\bar{E}$ rot $=-4.79 \times 10^{9} \mathrm{~J} \mathrm{~s}^{-1}$. Dressler [14] calculated a value which is about ten times larger. The negative value is interpreted as having a decelerating effect on the earth's rotation. By comparison, the deceleration in the Bering Sea as calculated by Sündermann [45] is about 45 times greater than that in the Gulf of California.

Since the friction term has a quadratic form, it is of interest to calculate the energy budget when the $M_{2}$ 

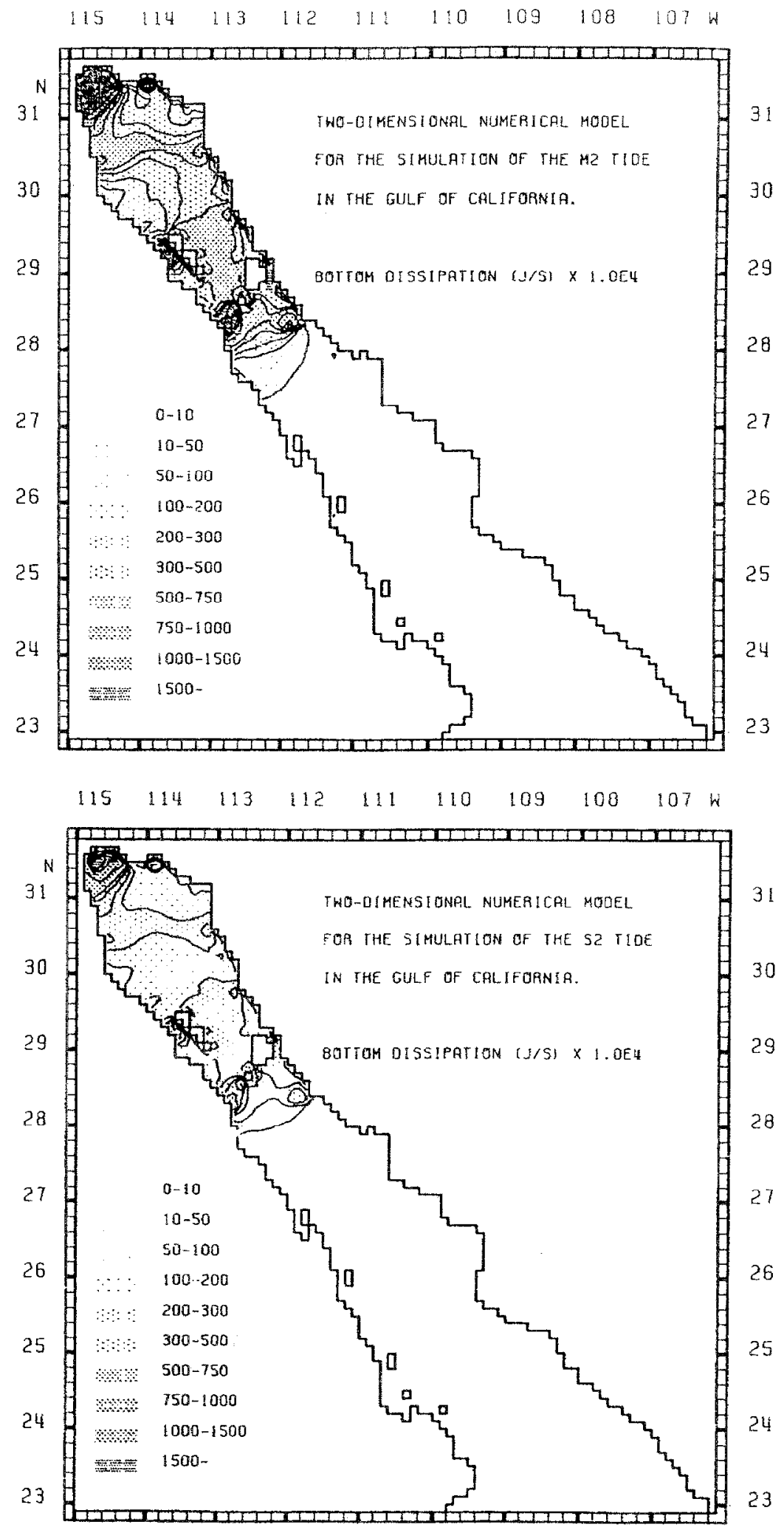

Figure 9. Distribution of rates of dissipation of tidal energy (for the $M_{2}$ and $S_{2}$ in $\mathrm{J} / \mathrm{s}$ ). The values indicate rates per grid point. 


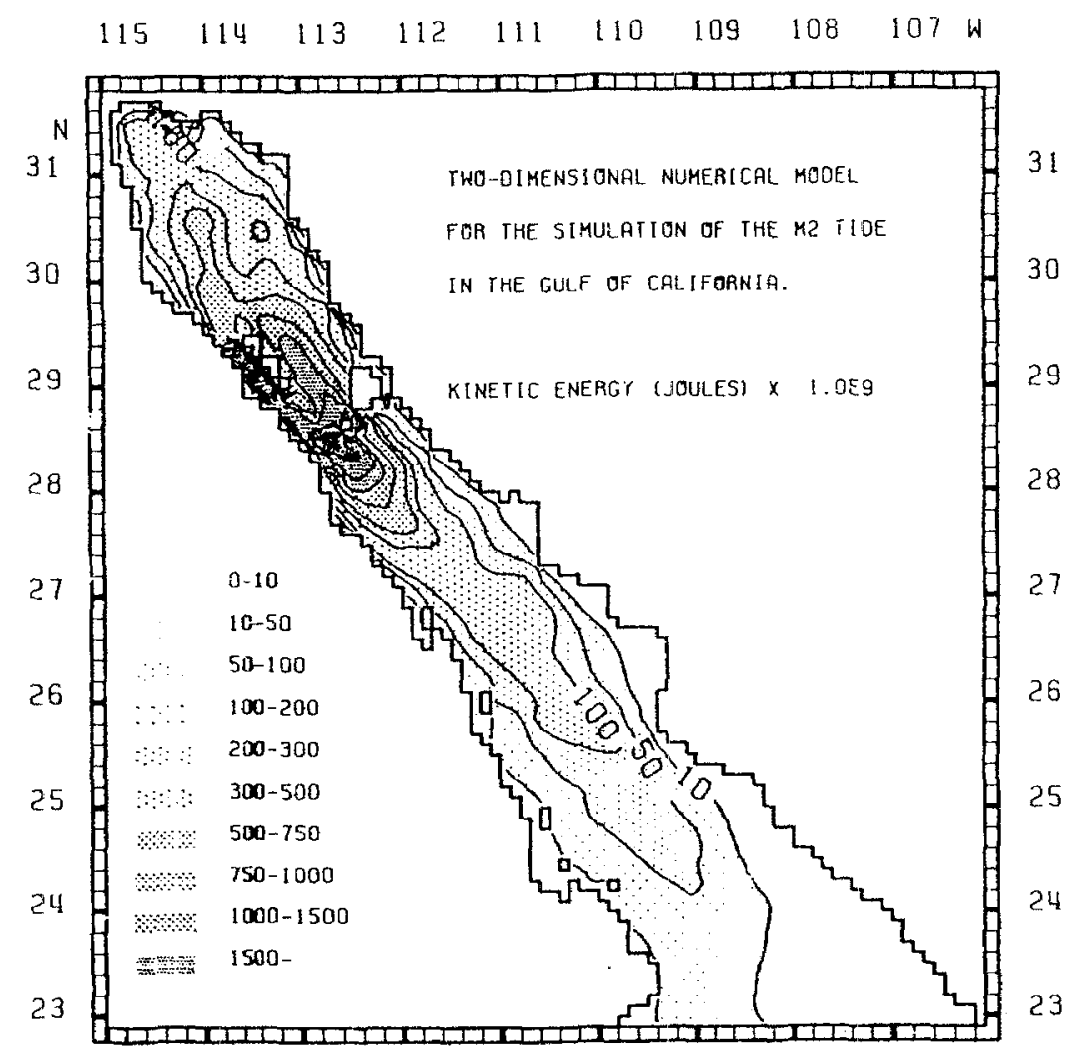

Figure 10. Distribution of average kinetical energy of the $M_{2}$ tide. The values mean energy content per grid point.

and $S_{2}$ are simultaneously simulated, i.e. when they can interact; and then to compare the results obtained in this way with the linear sum of energy parameters of the individual budgets. In this case, the energy was averaged in the modulation period of the $M_{2}$ and $S_{2}$. This period can be calculated by applying a simple formula [31] and has a value of $\approx 708$ hours. This time corresponds to 59 $\mathrm{S}_{2}$ and $57 \mathrm{M}_{2}$ periods. In table $I I I$, the results are given for these energy budgets. The values of the kinetic and potential energy are equal in the case of the linear sum of the individual budgets and when the $M_{2}$ and the $S_{2}$ are simultaneously simulated. Nor does the dissipation of energy due to turbulent viscocity change. The rate of energy dissipation due to bottom friction is, in the case of the simultaneous simulation, some $30 \%$ larger than the linear sum. These differences are significant in the northern part of the Gulf and between the islands of Tiburon and Angel de la Guarda. Therefore, the flow of energy into the Gulf must be stronger to compensate for this dissipation.

To obtain an idea of the interaction between the velucities of the $M_{2}$ and $S_{2}$ tides, the components of the velocity $u$ and $v$ (as calculated in separated form for the $M_{2}$ and $S_{2}$ ), were used to estimate the rate of energy dissipation. With $u=u_{M 2}+u_{s 2}$ and $v=V_{M 2}+V_{s 2}$ substituted in 10 , a value of $4.15 \times 10^{9}$ results. Although this value is of the same order as that given in table III (4\% larger), it is interpreted that the simultaneous simulation of the $M_{2}$ and $S_{2}$ tides slightly reduces the dissipation of energy. The results also indicate that, as expected, the nonlinear interaction between these two partial tides takes place predominantly through bottom friction.

\section{Estimation of periods of resonance}

In Section 2, the periods of resonance calculated for the Gulf of California were discussed. Although all values of the fundamental mode of resonance found in different works are comparable, it is difficult to decide which is nearer to the correct value. In an attempt to clarify this question, the same kind of experiments carried out by Stock [44] were repeated. Energy budgets for different forcing periodic signals were calculated. By varying the period of the driving signal (in steps less than a 
minute) and by comparing the average How of energy at the Gulf entrance obtained from all experiments, the fundamental and other resonance periods were estimated. In figure $11 a$, it can be seen that major average flows of energy occur for the periods of $14.57 \mathrm{~h}$ (fundamental period of resonance), $6.25,2.7,2.3$ and $1.65 \mathrm{~h}$. A signal reaching the Gulf with an amplitude of $30 \mathrm{~cm}$ (nearly the amplitude of the $\mathrm{M}_{2}$ tide) and a period of $14.57 \mathrm{~h}$ would undergo an amplification in the region of the Colorado River Delta of about 20 times. This mode is shown in figure $11 b$.

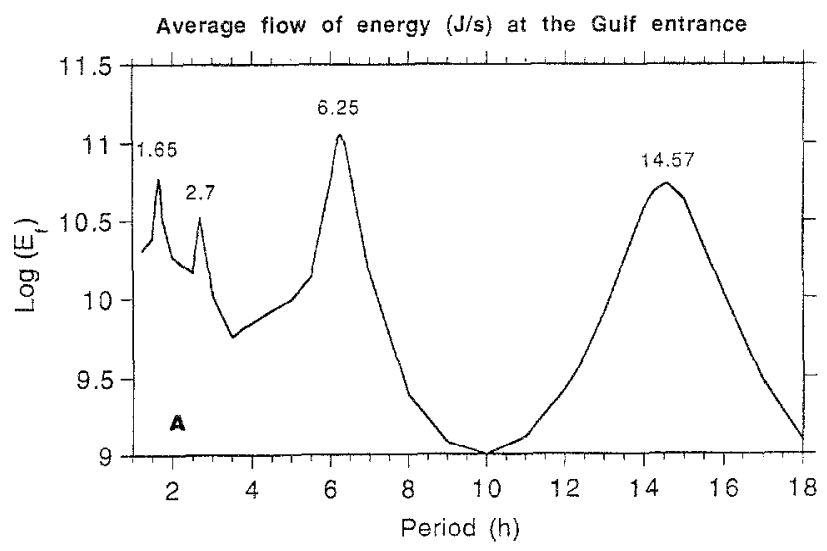

Figure 11. a: Average flow of energy at the Gulf entrance vs periods of the forcing signal. The amplitude at the Gulf entrance was in all experiments $30 \mathrm{~cm}$ and the phase $90^{\circ}$. b: Phases and amplitudes of the 14.57 mode.

\section{CONCLUSION}

In the present study, tides in the Gulf of California were successfully simulated with the application of a twodimensional semi-implicit model. In comparison with an explicit scheme, some $70 \%$ of computer time could be saved. Although the topography is very complex, it was possible to reproduce sea-surface elevations of the individually computed tidal components $M_{2}, S_{2}$ and $K_{1}$ quite accurately. Similar agreements were also reached when the seven most important tidal components were simultaneously simulated. Areas where the tidal flow is particularly intense were localized. The eulerian residual flow of the $M_{2}$ showed several intense gyres in the northern half of the Gulf. To a high degree of stationarity, the energy budget was calculated for the $M_{2}$ and $S_{2}$ tides. Most of the dissipation of tidal energy takes place in the shallow region of the Colorado River Delta, in the Ballenas Channel and over the Salsipuedes Sill. This explains why the best simulation of tides was obtained with a relatively high value for the friction coefficient. From all numerical experiments, much information (e.g., high values of kinetic energy in the Ballenas Channel and around the island of Angel de la Guarda, the successful simulation of a real spring-neap tidal cycle, the amplitudes of the $M_{2}$ and $M_{4}$ are of the same order in the Concepcion Bay, estimation of the period of resonance, etc.) was obtained. Our results coincide well with particular studies of tide effect, as in the agreement between the horizontal distribution of kinetic energy and patterns of mean sea-surface temperature in the archipelago region. The zone of intense flow in the Colorado River Delta also agrees with pictures of suspended sediment. It is hoped that these results will be beneficial for a more complete study of the circulation in the Gulf of California.

\section{Acknowledgements}

Thanks are due to Mrs. Ahrens, Mr. Geitner and Mr. Mühlenweg of the Institute of Oceanography, University of Hamburg, for their valued assistance. Noel Carbajal wishes to express his gratitude to the Consejo Nacional de Ciencia y Tecnologia (Mexico) for their financial support.

\section{REFERENCES}

[1] Argote M.L., Amador A., Lavín M., Tidal dissipation and stratification in the Gulf of California, J. Geophys. Res. 100 C8 (1995) 16,103-16,118.

[2] Backhaus J.O., A semi-implicit scheme for the shallow water equations for application to shelf sea modelling, Cont. Shelf Res. 2 (1983) 243-254.
[3] Badan-Dangon A., Koblinsky C.J., Baumgartner T., Spring and summer in the Gulf of California: Observation of surface thermal patterns, Oceanologica Acta. 8 (1985) 13-22.

[4] Brettschneider G.I., Anwendung des hydrodynamischnumerischen Verfahrens zur Ermittlung der $M_{2}$ Mitschwingungsgezeit der Nordsee, Mitt. Inst. Meeresk. Univ. Hamburg, Nr. VII (1967). 
[5] Brosche P., Sündermann J., Die Gezeiten des Meeres und die Rotation der Erde, Pure Appl. Geophys. 86 III (1971) 95-117.

[6] Carbajal N., Modelling of the circulation in the Gulf of California, Berichte aus dem Zentrum für Meeres- und Klimaforschung B 3 (1993).

[7] Carbajal N., Souza A., Durazo R., A Numerical study of the ex-ROFI of the Colorado River, J. Mar. Systems 12 1/4 (1997).

[8] Carbajal N., Two applications of Taylor's problem solution for finite rectangular semi-enclosed basins, Cont. Shelf Res. 177 (1996) 803-817.

[9] Castro R., Lavin M.F., Ripa P., Seasonal heat balance in the Gulf of California, J. Geophys. Res. 99 C2 (1994) 3249-3261.

[10] Crean P.B., Murty T.S., Stronach J.A., Mathematical modelling of tides and estuarine eirculation, in: Lecture Notes on Coastal and Estuarine Studies, 30 (1988) 471 p. Springer-Verlag.

[11] Defant A., Physical Oceanography, Vol. 2, Pergamon, Oxford (1961).

[12] Deutsches Hydrographisches Institut. Tafeln der Astronomisches Argumente $V_{0}+v$ und der Korrektionen $j, v, 2276$ (1967).

[13] Dietrich G., Kalle K., Krauss W., Siedler G., Allgemeine Meereskunde, Gebrüder Borntraeger, Berlin, Stuttgart (1975)

[14] Dressler R., Investigaciones sobre mareas y cfectos del vicnto en el Golfo de California mediante un modelo Hidrodinamiconumerico (HN) (1981).

[15] Duwe K.C., Ein semi-implizites Gezeitenmodell für Wattgebiete, Dt. Hydrogr. Z. 35 (1982) 223-238.

[16] Engel M., Hydrodynamisch-numerische Ermittlung von Bewegungsvorgänge im Schwarzen Meer, Mitt. Inst. Meeresk. Univ. Hamburg XXII (1974).

[17] Filloux J.H., Tidal patterns and energy balance in the Gulf of California, Nature 243 (1973) 217-221.

[18] Flather R.A., Results from a model of the north east Atlantic relating to the Norwegian coastal current, in: The Norwegian coastal current, R. Saetre and M. Mork (Eds), University of Bergen (1981) 427-458.

[19] Friedrich H., Numerische Berechnungen der allgemeinen Zirkulation im Meere nach einem Differenzverfahren, vornehmlich für den Atlantischen Ozean, Mitt. Inst. Meeresk. Univ. Hamburg III (1966).

[20] Fu L.-L., Holt B., Internal waves in the Gulf of California: Observations from a spaceborne radar, J. Geophys. Res. 89 C2 (1984) 2053-2060.

[21] Gaviño J., Free modes in the Gulf of California, (1997) in preparation.

[22] Garret C.J.R., Munk W.H., The age of the tide and the Q of the oceans, Deep-Sea Res. 18 (1971) 493-503.

[23] Gill A.E., Atmosphere-Ocean Dynamics, Academic press, San Diego, Calif, 1982, 662 p.

[24] Godin G., The resonant period of the Bay of Fundy, Cont. Shelf Res. 8 (1988) 8 1005-1010.
[25] Hansen W., Theorie zur Errechnung des Wasserstandes und der Strömungen in Randmeeren nebst Anwendungen, Tellus 8 (1956)

[26] Harms I., Eine Untersuchung des Randstroms an der nordwestenrnpäischen Shelfkante mit einem 7weidimensionalen Strömungsmodell, Dipl. Arb. Inst. Meeresk. Hamburg, $80 \mathrm{~S}$ (1988).

[27] Heaps N.S., Linearized vertically integrated equations for residual circulation in coastal seas, Dt. Hydrogr. Z. 31 (1978) 147-169.

[28] Heiskanen W., ber den Einfluss der Gezeiten auf die Säkulare Acceleration des Mondes, $\Lambda$ mer. $\Lambda$ cad. Sci. Fernicae $\Lambda 18$, 1 (1921)

[29] Hendershott M.C., Speranza A., Co-nscillating tides in long, narrow bays: The Taylor problem revisited, Deep-Sea Res. 18 (1971) 959-980.

[30] Karcher M., Untersuchungen zur Strömungen in der Norwegischen Rinne mit einem zweidimensionalen numerischen modell, Dipl. Arb. Inst. Meeresk. Hamburg 99 S (1988).

[31] Krauss W., Methods and results of theoretical Oceanography, part 1, Dynamics of the Homogeneous and the Quasihomogeneous Ocean, Gebrüder Borntraeger, Berlin, Stuttgart, 1973.

[32] Lavin M.F., Organista S., Surface heat flux in the northern Gulf of California, J. Geophys. Res. 93 C11 (1988) 14,3314,38 .

[33] Maier-Reimer E., Residual circulation in the North Sea due to the $M_{2}$-tide and mean annual wind stress, Dt. Iydrogr. Z. 32 (1977) 126-130.

[34] Mihardja D.K., Energy and momentum budget of the tides in Indonesian waters, Berichte aus dem Zentrum für Meeresund Klimaforschung der Univ. Hamburg, 14 (1991).

[35] Miller G.R., The flux of tidal energy out of the deep oceans, J. Geophys. Res. 71 (1966) 2485.

[36] Morales R.A., Mapas de isolinias de constantes armonicas de marea del Gulfo de California, tesis, Universidad autonoma de Baja California, Escuela Superior de Cicncias Marinas (1983).

[37] Morales R.A., Gutierrez G., Mareas en el Golfo de California, Geof. Int. 28-1 (1989) 25-46.

[38] Paden C.A., Abbot M.R., Winant C.D., Tidal and atmospheric forcing of the upper ocean in the Gulf of California 1. Sea surface temperature variability, J. Geophys. Res. 96 C10 (1991) 18,337-18,359.

[39] Pingree R.D., Maddock L., Tidal residual in the English Channel, J. Mar. Biol. Ass. U.K. 57 (1977) 339-354.

[40] Quiros G.A. Badan-Dangon, Ripa P., $M_{2}$ Currents and residual flow in the Gulf of California, Neth. J. Sea Res. 284 (1992) 251-259.

[41] Roden G.I., Groves G.W., Recent oceanographic observations in the Gulf of California, J. Mar. Res. 18 (1959) 10-35.

[42] Schwiderski E.W., Ocean Tides, Part I: Global Ocean Tidal Equation, Marine Geodesy. (1980) 161-217.

[43] Simpson J.H., Souza A.J., Lavín M.F., Tidal mixing in the Gulf of California, in Mixing and Transport in the 
Environment, K.J. Beven, P.C. Chatwin and J.H. Millbank (Eds). John Wiley and Sons Ltd. 1994.

[44] Stock G.G., Modelling of tides and tidal dissipation in the Gulf of California, Ph. D. thesis, Scripps Inst. Oceanogr., Univ Calif., San Diego, 1976, 102 p.

[45] Sündermann J., Die hydrodynamisch- numerische Berechnung der Vertikalstruktur von Bewegungsvorgängen in Kanälen und Becken, Mitt. Inst. Meeresk. Univ. Hamburg 19101 S (1971).

[46] Sündermann J., The semidiurnal principal lunar tide $M_{2}$ in the Bering Sea, Dt. Hydrogr. Z. 3 (1977) 91-101.

[47] Tablas de Prediccion de Marcas, Datos gcofisicos scric A, oceanografia, Instituto de Geofisica, Universidad Nacional Autónoma de México (1985).
[48] 'laylor G.l., 'lidal oscillations in gults and rectangular basins, Proc. London Mat. Soc. 20 (1921) 148-181.

[49] Tee K.T., Tide-induced residual current- Verification of a numerical model, J. Mar. Res. 344 (1976) 603-628.

[50] Trepka von L., Anwendung des hydrodynarnisch-numerischen Verfahrens zur Ermittlung des Schelfeinflusses auf die Gezeiten in Modellkanälen und und Modellozeanen, Mitt. Inst. Meeresk. Univ. Hamburg 9 (1967).

[51] Zahel W., Mathematical and physical characteristics and recent results of ocean tide models, in: Lecture Notes in Physics 58 (1976) 349-367.

[52] Zimmerman J.T.F., Topographic generation of residual circulation by oscillatory (tidal) current, Geophys. Astr. Fl. Dyn. 11 (1978) 35-47. 